\title{
Displacement and Stress Analysis of Thin Plate for Cement Concrete Pavement
}

\author{
Liang Jia $\mathbb{D}^{1},{ }^{1}$ Li Zhang, ${ }^{1}$ Jian Guo, ${ }^{1}$ Kai Yao $\mathbb{D},{ }^{2}$ and Shikai He ${ }^{1}$ \\ ${ }^{1}$ College of Civil Engineering, Lanzhou University of Technology, Lanzhou 730050, China \\ ${ }^{2}$ Department of Civil \& Environmental Engineering, National University of Singapore, Singapore 117576
}

Correspondence should be addressed to Kai Yao; yaokai@u.nus.edu

Received 12 January 2018; Revised 9 April 2018; Accepted 15 April 2018; Published 29 May 2018

Academic Editor: Fazal M. Mahomed

Copyright (c) 2018 Liang Jia et al. This is an open access article distributed under the Creative Commons Attribution License, which permits unrestricted use, distribution, and reproduction in any medium, provided the original work is properly cited.

In order to analyze the displacement and stress of thin plate for cement concrete pavement with rectangle shape and resting on Winkler soil foundation, an analysis model was set up based on the theory of elastic thin plate on Winkler foundation. According to elasticity Kirchhoff theory of thin plates and Winkler soil foundation model, the expressions of displacement and stress were yielded by using the inverse Hankel transform. Numerical method was employed to calculate displacement and stress of the thin plate. Results showed that displacement and stress corresponded with using the method from Code for Highway Design-Pavement. Results showed that the method can provide a new computation method for displacement and stress of the thin plate about cement concrete pavement.

\section{Introduction}

The model of a thin plate on elastic foundation was mainly used in structural engineering in last years. Currently, thin plates or films of metal, ceramic, or synthetic materials were bonded in the surface of machine structural parts or electronic devices to improve their mechanical, thermal, electronic, or tribological properties [1]. At these applications, the subgrade of the thin plate can be simulated as a Winkler foundation, which reacted with pressure proportional to the deflection of the plate at each point. The plate in the above applications was loaded by vertical loads or bending moments. For cement concrete pavement, the applied load is mainly from the vehicles, which is vertically applied on pavement. So that the width and thickness of the pavement are usually determined by the traffic volume. And the thickness will increase with the designed traffic volume. A large number of research works have been published to solve problem of a classical thin plate [2-4] or a thin plate on an elastic foundation [5-9]. Fisher investigated the elastic impact of a sphere on a thin plate which is continuous contact with a foundation [10]. Jedrysiak investigated the dynamic response of thin elastic plates in Winkler foundation [11].
Some researches introduced an efficient boundary element approach for the analysis of thin plate resting on an elastic Winkler foundation with different boundary conditions [1215]. Shao combined the Fourier spectral method and differential quadrature method for solving problems for thin plates resting on Winkler foundations with irregular domains [16].

However, few research works have been published concerning the stress and displacement of a thin plate on Winkler foundation. The present work is aimed to obtain an analytical solution of a finite rectangle thin plate on an elastic foundation under vertical forces. For this purpose, both the Hankel transform and inverse Hankel transform were adopted.

\section{Basic Assumption and Governing Equations}

According to the theory of elastic thin plate on Winkler soil foundation, a rectangle thin plate with thickness $h$ was considered to rest on a Winkler soil foundation (Figure 1), the thickness of plate was less than one-fifth the size of plane, the plate was loaded by the vertical pressure $q(x, y)$ and the foundation reaction pressure $p$ assumed to be proportional 


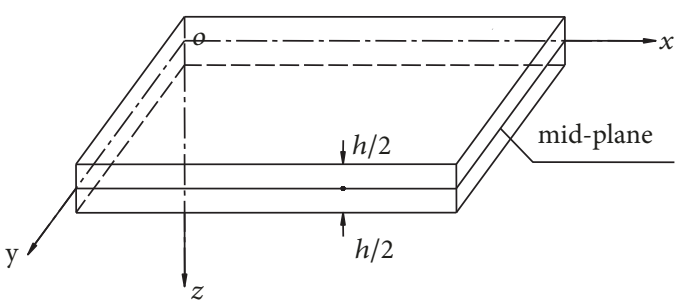

FIgURE 1: Model of the thin plate.

to the vertical deflection $\omega(x, y)$ of the plate [17], and the rectangular coordinate system was placed on midplane.

Kirchhoff proposed the basic assumption of the thin plate as follows [17].

(1) Length of normal line of the plate is unchanged before and after deformation, that is,

$$
\varepsilon_{\mathrm{z}}=0
$$

where $\varepsilon_{\mathrm{z}}$ is normal strain.

(2) Before deformation, the normal line of the plate is perpendicular to midplane; after deformation, the normal line is still perpendicular to midplane, that is,

$$
\begin{aligned}
& \gamma_{\mathrm{zx}}=0, \\
& \gamma_{\mathrm{zy}}=0
\end{aligned}
$$

where $\gamma_{z x}, \gamma_{z y}$ are shear strain.

(3) The plane of parallel to midplane does not squeeze, that is,

$$
\sigma_{\mathrm{z}}=0
$$

where $\sigma_{\mathrm{z}}$ is stress.

(4) Horizontal displacement of the midplane does not occur during the process thin plate bending, which are

$$
\begin{aligned}
& u_{0}=0, \\
& v_{0}=0
\end{aligned}
$$

where $u_{0}, v_{0}$ are displacement.

According to the hypothesis (2), it yields

$\gamma_{\mathrm{zx}}=0$, namely, $\partial w / \partial x+\partial u / \partial z=0$,

$\gamma_{\mathrm{zy}}=0$, namely, $\partial w / \partial y+\partial v / \partial z=0$.

Thus,

$$
\begin{aligned}
& u=-z \frac{\partial \omega}{\partial x}+u_{0} \\
& v=-z \frac{\partial \omega}{\partial y}+v_{0}
\end{aligned}
$$

According to the hypothesis (4), the displacement of thin plate can be obtained as follows:

$$
\begin{aligned}
& u=-z \frac{\partial \omega}{\partial x} \\
& v=-z \frac{\partial \omega}{\partial y}
\end{aligned}
$$

According to (6), the strain of thin plate can be obtained as follows:

$$
\begin{aligned}
\varepsilon_{x} & =\frac{\partial u}{\partial x}=-z \frac{\partial^{2} \omega}{\partial x^{2}} \\
\varepsilon_{y} & =\frac{\partial v}{\partial y}=-z \frac{\partial^{2} \omega}{\partial y^{2}} \\
\gamma_{x y} & =\frac{\partial u}{\partial y}+\frac{\partial v}{\partial x}=-2 z \frac{\partial^{2} \omega}{\partial x \partial y}
\end{aligned}
$$

According to general Hook's law, we can obtain

$$
\begin{aligned}
\varepsilon_{x} & =\frac{1}{E}\left[\sigma_{x}-\mu\left(\sigma_{y}+\sigma_{z}\right)\right] \\
\varepsilon_{y} & =\frac{1}{E}\left[\sigma_{y}-\mu\left(\sigma_{x}+\sigma_{z}\right)\right] \\
\gamma_{x y} & =\frac{1}{E}\left[\sigma_{z}-\mu\left(\sigma_{x}+\sigma_{y}\right)\right]
\end{aligned}
$$

Substituting (7) into (8), the stress of thin plate can be obtained as follows:

$$
\begin{aligned}
\sigma_{x} & =-\frac{E z}{1-\mu^{2}}\left(\frac{\partial^{2} \omega}{\partial x^{2}}+\mu \frac{\partial^{2} \omega}{\partial y^{2}}\right) \\
\sigma_{y} & =-\frac{E z}{1-\mu^{2}}\left(\frac{\partial^{2} \omega}{\partial y^{2}}+\mu \frac{\partial^{2} \omega}{\partial x^{2}}\right) \\
\tau_{x y} & =-\frac{E z}{1+\mu} \frac{\partial^{2} \omega}{\partial x \partial y}
\end{aligned}
$$

where $E$ is elasticity modulus, $\mu$ is Poisson's ratio, $u$ and $v$ are displacement, $\omega$ is vertical deflection of the plate, and $\omega=$ $\omega(x, y)$.

\section{Stress Fields of the Elastic Thin Plate}

A stress field is a region in a body for which the stress is defined at every point [18]. Stress fields were widely used in materials science. The stress field, which was composed of these generalized stresses, was called the generalized stress field.

A hexahedron element with thickness $h$ was taken out from the thin plate (Figure 2); stress components acting on the four sides of hexahedron element were $M_{x} d y, M_{y} d x$, $M_{x y} d y, M_{y x} d x, Q_{x} d y$, and $Q_{y} d x$, where $M_{x}, M_{y}, M_{x y}, M_{y x}, Q_{x}$, and $Q_{y}$ are called the generalized stress. Generalized stress can be expressed as follows:

$$
\begin{aligned}
& M_{x}=-\int_{-\mathrm{h} / 2}^{\mathrm{h} / 2} \sigma_{\mathrm{x}} \mathrm{z} d z \\
& M_{y}=-\int_{-\mathrm{h} / 2}^{\mathrm{h} / 2} \sigma_{\mathrm{y}} \mathrm{z} d z \\
& M_{x y}=M_{y x}=-\int_{-\mathrm{h} / 2}^{\mathrm{h} / 2} \tau_{x y} \mathrm{z} d z
\end{aligned}
$$




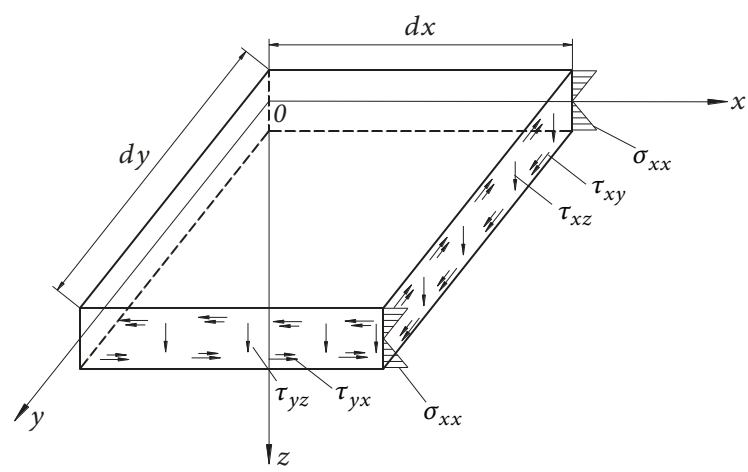

FIGURE 2: Stress of the plane.

$$
\begin{aligned}
& Q_{x}=-\int_{-\mathrm{h} / 2}^{\mathrm{h} / 2} \tau_{\mathrm{zx}} d z \\
& Q_{y}=-\int_{-\mathrm{h} / 2}^{\mathrm{h} / 2} \tau_{\mathrm{zy}} d z
\end{aligned}
$$

Substituting (9) into (10) yields

$$
\begin{aligned}
M_{x} & =-D\left(\frac{\partial^{2} \omega}{\partial x^{2}}+\mu \frac{\partial^{2} \omega}{\partial y^{2}}\right) \\
M_{y} & =-D\left(\frac{\partial^{2} \omega}{\partial y^{2}}+\mu \frac{\partial^{2} \omega}{\partial x^{2}}\right) \\
M_{x y} & =-D(1-\mu) \frac{\partial^{2} \omega}{\partial x \partial y} \\
Q_{x} & =-D \frac{\partial\left(\nabla^{2} \omega\right)}{\partial x} \\
Q_{y} & =-D \frac{\partial\left(\nabla^{2} \omega\right)}{\partial y}
\end{aligned}
$$

where $\nabla^{2}=\partial^{2} / \partial x^{2}+\partial^{2} / \partial y^{2}, \nabla^{2}$ is the Laplacian operator, $D=E h^{3} / 12\left(1-\mu^{2}\right)$, and $D$ is relative stiffness of the plate.

Combining (9) and (11) gives

$$
\begin{aligned}
\sigma_{x} & =\frac{12 M_{x} z}{h^{3}} \\
\sigma_{y} & =\frac{12 M_{y} z}{h^{3}} \\
\tau_{x y} & =\frac{12 M_{x y} z}{h^{3}} \\
\tau_{z x} & =-\frac{6 Q_{x}}{h^{3}}\left(\frac{h^{2}}{4}-z^{2}\right) \\
\tau_{z y} & =-\frac{6 Q_{y}}{h^{3}}\left(\frac{h^{2}}{4}-z^{2}\right)
\end{aligned}
$$

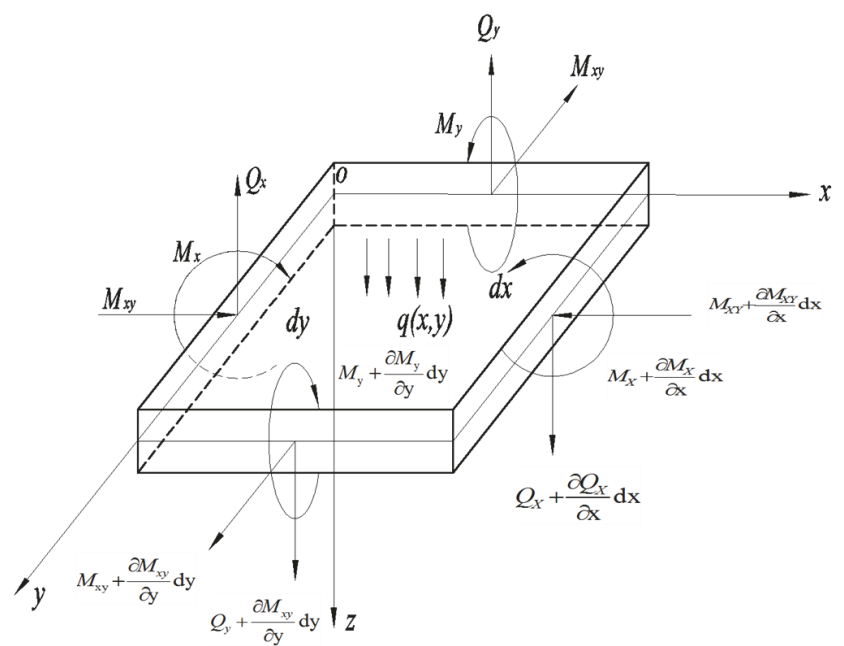

FIGURE 3: Internal force of the plane.

Under the condition of axisymmetric loading, stress of the plane can be obtained

$$
\begin{aligned}
& M_{r}=-D\left(\frac{d^{2} w}{d r^{2}}+\frac{\mu}{r} \frac{d w}{d r}\right) \\
& M_{\theta}=-D\left(\mu \frac{d^{2} w}{d r^{2}}+\frac{1}{r} \frac{d w}{d r}\right)
\end{aligned}
$$

\section{Bending Equations of the Thin Plate}

As illustrated in Figure 3, uniform load $q(x, y)$ is applied on hexahedron element, while $M_{x}, M_{y}, M_{x y}, M_{y x}, Q_{x}$, and $Q_{y}$ are generalized stress on the four sides of the element.

The loading added up to zero in the direction of the $z$ axis, and solving bending moments of parallel to the $x$ axis and the $y$ axis yields

$$
\begin{aligned}
Q_{x} & =\frac{\partial M_{x}}{\partial x}+\frac{\partial M_{x y}}{\partial y} \\
Q_{y} & =\frac{\partial M_{y}}{\partial y}+\frac{\partial M_{x y}}{\partial x} \\
\frac{\partial Q_{x}}{\partial x}+\frac{\partial Q_{y}}{\partial y}+q & =0
\end{aligned}
$$

Substituting (14) and (15) into (16) yields

$$
\frac{\partial^{2} M_{x}}{\partial x^{2}}+2 \frac{\partial^{2} M_{x y}}{\partial x \partial y}+\frac{\partial^{2} M_{y}}{\partial y^{2}}+q=0
$$

Substituting (11) into (17) yields

$$
\mathrm{D} \nabla^{2} \nabla^{2} \omega(\mathrm{x}, \mathrm{y})=q(x, y)
$$

where $\nabla^{2}=\partial^{2} / \partial x^{2}+\partial^{2} / \partial y^{2}, \nabla^{2}$ is the Laplace operator.

According to the view of Winkler [1], a rectangle thin plate was considered to rest on a Winkler soil foundation, 
and the foundation reaction pressure $p$ was only related to the vertical deflection $\omega$ of the plate.

$$
p=k \omega
$$

where $k$ is reaction modulus of the foundation.

The plate was loaded as follows:

$$
q(x, y)-k \omega(x, y)
$$

A finite elastic thin plate on Winkler soil foundation; the bending equation was obtained as follows:

$$
\mathrm{D} \nabla^{2} \nabla^{2} \omega(\mathrm{x}, \mathrm{y})=q(\mathrm{x}, \mathrm{y})-k \omega(x, y)
$$

\section{The Equations of Stress and Displacement}

Under the axisymmetric loading, the bending equation of the thin plate on Winkler soil foundation in cylindrical can be obtained as follows:

$$
D \nabla^{2} \nabla^{2} \omega(r)=q(r)-k w(r)
$$

where $\nabla^{2}=\left(d^{2} / d r^{2}+(1 / r)(d / d r)\right)$.

The application of the first class of zero order Hankel transform to equation (22) yields

$$
D \xi^{4} \bar{\omega}(\xi)+k \bar{\omega}(\xi)=\bar{q}(\xi)
$$

where $\bar{\omega}(\xi)=\int_{0}^{\infty} \omega(r) J_{0}(\xi r) r d r, \bar{q}(\xi)=\int_{0}^{\infty} q(r) J_{0}(\xi r) r d r$

Solution for (23) yields [17]

$$
\bar{\omega}(\xi)=\frac{\bar{q}(\xi)}{D \xi^{4}+k}
$$

where $D=E h^{3} / 12\left(1-\mu^{2}\right)$.

Set $l^{4}=D / k ; l$ is the relative stiffness radius of the plate on Winkler soil foundation. The application of Hankel transform to (24) and expression of deflection can be obtained as follows.

$$
\omega(r)=\frac{1}{k} \int_{0}^{\infty} \frac{\bar{q}(\xi) J_{0}(\xi r)}{1+l^{4} \xi^{4}} \xi d \xi
$$

Substituting (25) into (13) yields

$$
\begin{aligned}
& M_{r}=-D\left(\frac{d^{2} \omega(r)}{d r^{2}}+\frac{\mu}{r} \frac{d \omega(r)}{d r}\right) \\
& =l^{4} \int_{0}^{\infty} \frac{\bar{q}(\xi) J_{0}(\xi r)}{1+l^{4} \xi^{4}}\left[\xi J_{0}(\xi r)-\frac{1-\mu}{r} J_{1}(\xi r)\right] \xi^{2} d \xi \\
& M_{\theta}=-D\left(\mu \frac{d^{2} \omega}{d r^{2}}+\frac{1}{r} \frac{d \omega}{d r}\right) \\
& =l^{4} \int_{0}^{\infty} \frac{\bar{q}(\xi) J_{0}(\xi r)}{1+l^{4} \xi^{4}}\left[\mu \xi J_{0}(\xi r)+\frac{1-\mu}{r} J_{1}(\xi r)\right] \xi^{2} d \xi
\end{aligned}
$$

The maximum radial stress $\sigma_{r}$ and tangential stress $\sigma_{\theta}$ can be obtained as follows:

$$
\begin{gathered}
\sigma_{r}=\frac{6 M_{r}}{h^{2}} \\
\sigma_{\theta}=\frac{6 M_{\theta}}{h^{2}}
\end{gathered}
$$

On the position $r=0$, (25)-(27)can be transformed as follows:

$$
\begin{aligned}
\omega(r) & =\frac{1}{k} \int_{0}^{\infty} \frac{\bar{q}(\xi)}{1+l^{4} \xi^{4}} \xi d \xi \\
M_{r} & =l^{4} \int_{0}^{\infty} \frac{\bar{q}(\xi)}{1+l^{4} \xi^{4}} \xi^{3} d \xi \\
M_{\theta} & =l^{4} \int_{0}^{\infty} \frac{\bar{q}(\xi)}{1+l^{4} \xi^{4}} \mu \xi^{3} d \xi
\end{aligned}
$$

Equations (30)-(32) can be solved by numerical method. Combining equations (31) and (32) gives

$$
M_{\theta}=\mu M_{r}
$$

The thin plate for cement concrete pavement, $\mu$, was less than 1. Therefore, $\sigma_{r}$ was greater than $\sigma_{\theta}$ on the position $r=0$. The maximum stress $\sigma_{r}$ was calculated in the following example.

\section{Calculation Example}

In order to check the validity of the method presented in the paper, an example of thin plate for cement concrete pavement was given. The material parameters were chosen as follows: $h=0.18 \mathrm{~m}$ and $h=0.22 \mathrm{~m}, E=11000 \mathrm{MPa}, \mu=0.15, k=$ $1.4 \times 10^{7} \mathrm{~N} / \mathrm{m}^{3}, \delta=0.151 \mathrm{~m} q(x, y)=0.7 \mathrm{MPa}$. We selected the integral interval changed from $0-10,0-20,0-30,0-40,0$ 50 , and $0-1000$, respectively, the displacement and stress were calculated, and the results were summarized in Tables 1, 2, 3, and 4 .

According to the result of Table 1, integral interval tends to $0-20$; when the thickness $h$ of the thin plate is from $0.18 \mathrm{~m}$ to $h=0.22 \mathrm{~m}$, displacement of the thin plate on the position $r=0$ was $0.615 \mathrm{~mm}$ and $0.595 \mathrm{~mm}$, respectively. According to the results of Table 2, integral interval tends to $0-40$; when the thickness $h$ of the thin plate is from $0.18 \mathrm{~m}$ to $h=0.22 \mathrm{~m}$, stress of the thin plate on the position $r=0$ was $1.53 \mathrm{MPa}$ and $1.41 \mathrm{MPa}$, respectively.

\section{Validation of the Method}

The material parameters were chosen as the calculation example; according to the literature [19], calculation procedure was as follows.

Relative stiffness radius $l$ of the pavement is

$$
\begin{aligned}
& l_{h=0.18 m}=\sqrt[4]{\frac{E h^{3}}{12\left(1-\mu^{2}\right) k}}=0.25 \mathrm{~m} \\
& l_{h=0.22 m}=\sqrt[4]{\frac{E h^{3}}{12\left(1-\mu^{2}\right) k}}=0.42 \mathrm{~m}
\end{aligned}
$$

Based on this, we can obtain coefficient $\alpha$ :

$$
\begin{gathered}
\alpha_{h=0.18 m}=\frac{\delta}{l_{h=0.18 m}}=0.604 \\
\alpha_{h=0.22 m}=\frac{\delta}{l_{h=0.18 m}}=0.356
\end{gathered}
$$


TABLE 1: Displacement of plate in the middle position $(h=0.18 \mathrm{~m})$.

\begin{tabular}{lccccc}
\hline integration interval & $0-10$ & $0-20$ & $0-30$ & $0-40$ & $0-50$ \\
\hline $\begin{array}{l}\text { displacement of the plate in the } \\
\text { middle position } / \mathrm{mm}\end{array}$ & 0.614963 & 0.615458 & 0.615507 & 0.615473 & 0.615469 \\
\hline
\end{tabular}

TABLE 2: Stresses of plate in the middle position $(h=0.18 \mathrm{~m})$.

\begin{tabular}{llllll}
\hline integration interval & $0-10$ & $0-20$ & $0-30$ & $0-40$ & $0-50$ \\
\hline $\begin{array}{l}\text { stress of the plate in the middle } \\
\text { position /MPa }\end{array}$ & 1.46 & 1.53 & 1.54 & 1.53 & 1.53 \\
\hline
\end{tabular}

TABLE 3: Displacement of plate in the middle position $(h=0.22 \mathrm{~m})$.

\begin{tabular}{lccccc}
\hline integration interval & $0-10$ & $0-20$ & $0-30$ & $0-40$ & $0-50$ \\
\hline $\begin{array}{l}\text { displacement of the plate in the } \\
\text { middle position } / \mathrm{mm}\end{array}$ & 0.594542 & 0.595469 & 0.595564 & 0.595535 & 0.595531 \\
\hline
\end{tabular}

TABLE 4: Stresses of plate in the middle position $(h=0.22 \mathrm{~m})$.

\begin{tabular}{lccccc}
\hline integration interval & $0-10$ & $0-20$ & $0-30$ & $0-40$ & $0-50$ \\
$\begin{array}{l}\text { stress of the plate in the middle } \\
\text { position / MPa }\end{array}$ & 1.35 & 1.41 & 1.42 & 1.41 & 1.41 \\
\hline
\end{tabular}

The deflection of the thin plate on the position $r=0$ can be found in the table [19].

$$
\begin{aligned}
& \alpha=0.604, \\
& \omega=1.23 \times 10^{-2} \\
& \alpha=0.356, \\
& \omega=1.19 \times 10^{-2}
\end{aligned}
$$

Deflection of the plate on the position $r=0$ can be obtained as follows:

$$
\begin{aligned}
& \omega_{h=0.18 m}=\frac{p}{k} \omega=\frac{0.7}{14} \times 1.23 \times 10^{-2}=6.15 \times 10^{-4} \mathrm{~m} \\
& \omega_{h=0.22 m}=\frac{p}{k} \omega=\frac{0.7}{14} \times 1.19 \times 10^{-2}=5.95 \times 10^{-4} \mathrm{~m}
\end{aligned}
$$

The bending moment coefficient on the position $r=0$ can be found in the table [19].

$$
\begin{aligned}
\alpha & =0.604, \\
\overline{M_{r}} & =0.172 \\
\alpha & =0.356, \\
\overline{M_{r}} & =0.237
\end{aligned}
$$

Bending moment of the plate on the position $r=0$ can be obtained as follows:

$$
\begin{aligned}
M_{r h=0.18 m} & =p \overline{M_{r}}=48 \times 10^{3} \times 0.172=8.26 \times 10^{3} \mathrm{~N} \\
M_{r h=0.22 m} & =p \overline{M_{r}}=48 \times 10^{3} \times 0.237 \\
& =11.37 \times 10^{3} \mathrm{~N}
\end{aligned}
$$

Radial stress of the plate on the position $r=0$ can be obtained as follows:

$$
\begin{aligned}
& \sigma_{r h=0.18 m}=\frac{6 M_{r}}{h^{2}}=\frac{6 \times 8.26 \times 10^{3}}{0.18^{2}}=1.53 \mathrm{MPa} \\
& \sigma_{r h=0.22 m}=\frac{6 M_{r}}{h^{2}}=\frac{6 \times 11.37 \times 10^{3}}{0.22^{2}}=1.41 \mathrm{MPa}
\end{aligned}
$$

From the above analysis, the stress and deflection based on the method were equal to using the method from Code for Highway Design-Pavement [19]. It also indicated that the present method was reasonable in the paper.

\section{Conclusions}

(1) The expressions of displacement and stress for cement concrete pavement on elastic foundation were derived.

(2) In order to verify the theoretical results, an example of thin plate for cement concrete pavement was given; the stress and deflection correspond with using the method from Code for Highway Design-Pavement.

(3) Future experiment research is needed to be carried out to verify the theoretical results present in this paper.

\section{Data Availability}

All the data used to support the findings of this study are included within the article.

\section{Conflicts of Interest}

The authors declare that they have no conflicts of interest. 


\section{Acknowledgments}

This work was supported by the National Natural Science Foundation of China (Grant no. 51568044).

\section{References}

[1] D. G. Pavlou, "Green's function for a pre-stressed thin plate on an elastic foundation under axisymmetric loading," Engineering Analysis with Boundary Elements, vol. 29, no. 5, pp. 428-434, 2005.

[2] M. V. Delyavs'kyi, N. V. Zdolbits'ka, L. I. Onyshko, and A. P. Zdolbits'kyi, "Determination of the stress-strain state in thin orthotropic plates on Winkler's elastic foundations," Journal of Materials Science, vol. 50, no. 6, pp. 782-791, 2015.

[3] L. De Oliveira Neto and J. B. De Paiva, "Cubic approximation for the transverse displacement in BEM for elastic plates analysis," Engineering Analysis with Boundary Elements, vol. 28, no. 7, pp. 869-880, 2004.

[4] L. P. Jr, "Plate bending analysis using the classical or the Reissner-Mindlin models," Engineering Analysis with Boundary Elements, vol. 27, no. 6, pp. 603-609, 2003.

[5] W. Yu and F. Chen, "Global bifurcations and homoclinic trees in motion of a thin rectangular plate on a nonlinear elastic foundation," Meccanica, vol. 48, no. 5, pp. 1251-1261, 2013.

[6] M. Utku, E. Çitipitioglu, and I. Inceleme, "Circular plates on elastic foundations modelled with annular plates," Computers \& Structures, vol. 78, no. 1, pp. 365-374, 2000.

[7] K. Chandrashekhara and S. J. Antony, "Elastic analysis of an annular slab-soil interaction problem using a hybrid method," Computers \& Geosciences, vol. 20, no. 2, pp. 161-176, 1997.

[8] T. Morimoto and Y. Tanigawa, "Elastic stability of inhomogeneous thin plates on an elastic foundation," Archive of Applied Mechanics, vol. 77, no. 9, pp. 653-674, 2007.

[9] F. Cafarella, "Thin plates on elastic foundation with unilateral behaviour," Meccanica, vol. 7, no. 1, pp. 39-39, 1972.

[10] H. D. Fisher, "The impact of an elastic sphere on a thin elastic plate supported by a winkler foundation," Journal of Applied Mechanics, vol. 42, no. 1, pp. 133-135, 1975.

[11] J. Jedrysiak, "Dynamics of thin periodic plates resting on a periodically inhomogeneous Winkler foundation," Archive of Applied Mechanics, vol. 69, no. 5, pp. 345-356, 1999.

[12] A. Joodaky, I. Joodaky, M. Hedayati, R. Masoomi, and E. B. Farahani, "Corrigendum to "Deflection and stress analysis of thin FGM skew plates on Winkler foundation with various boundary conditions using extended Kantorovich method," Composites, vol. 51, no. 3, pp. 191-196, 2013.

[13] A. El-Zafrany, S. Fadhil, and K. Al-Hosani, "A new fundamental solution for boundary element analysis of thin plates on Winkler foundation," International Journal for Numerical Methods in Engineering, vol. 38, no. 6, pp. 887-903, 1995.

[14] Z. Yang and W. Li, "Subharmonic resonance of rectangular thin plate with four sides free on Winkler foundation and its singularity analysis," Journal of Mechanical Strength, vol. 29, no. 2, pp. 329-333, 2007.

[15] A. Joodaky, I. Joodaky, M. Hedayati, R. Masoomi, and E. B. Farahani, "Deflection and stress analysis of thin FGM skew plates on Winkler foundation with various boundary conditions using extended Kantorovich method," Composites Part B: Engineering, vol. 51, pp. 191-196, 2013.
[16] W. Shao and X. Wu, "Fourier differential quadrature method for irregular thin plate bending problems on Winkler foundation," Engineering Analysis with Boundary Elements, vol. 35, no. 3, pp. 389-394, 2011.

[17] Z. Chuanchao and W. Binggang, Mechanical analysis of road structures, China Communications Press, Beijing, 2003.

[18] E. Lomakin, S. Alexandrov, and Y.-R. Jeng, "Stress and strain fields in rotating elastic/plastic annular discs," Archive of Applied Mechanics, vol. 86, no. 1-2, pp. 235-244, 2016.

[19] Y. Zukuang, Code for highway design-pavement, China Communications Press, Beijin, China, 3rd edition, 2003. 


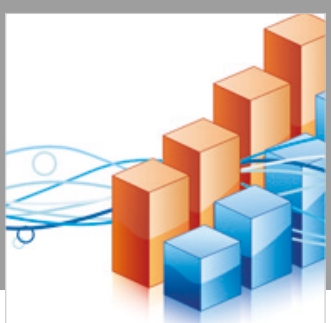

Advances in

Operations Research

\section{-n-m}
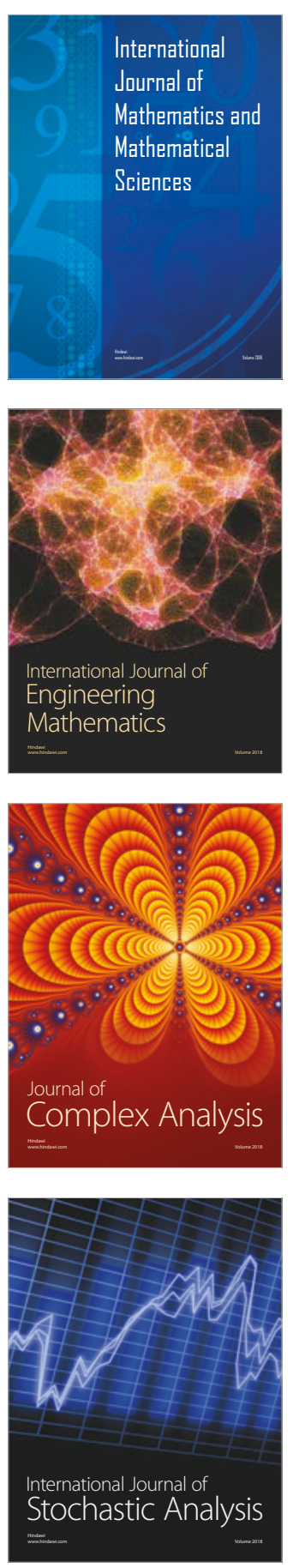
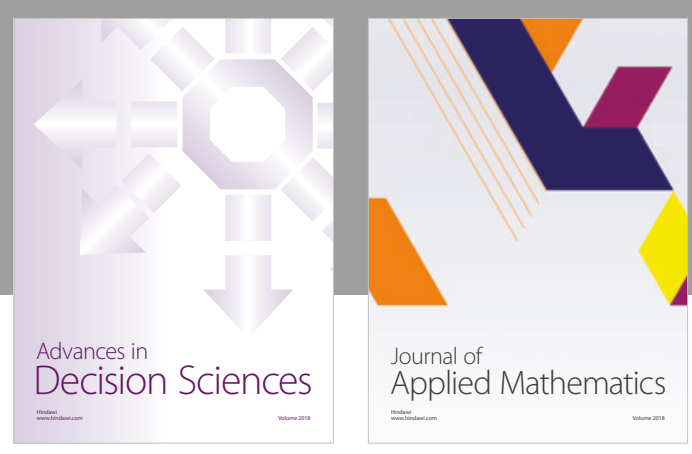

Journal of

Applied Mathematics
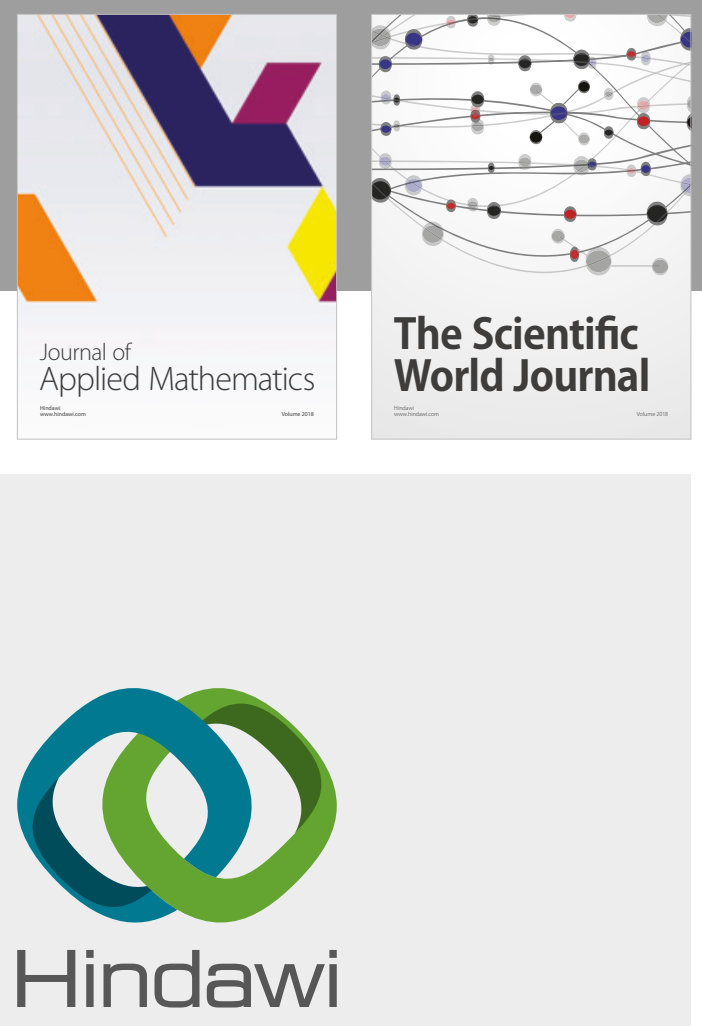

Submit your manuscripts at

www.hindawi.com

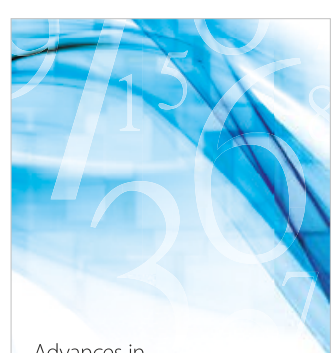

Advances in
Numerical Analysis
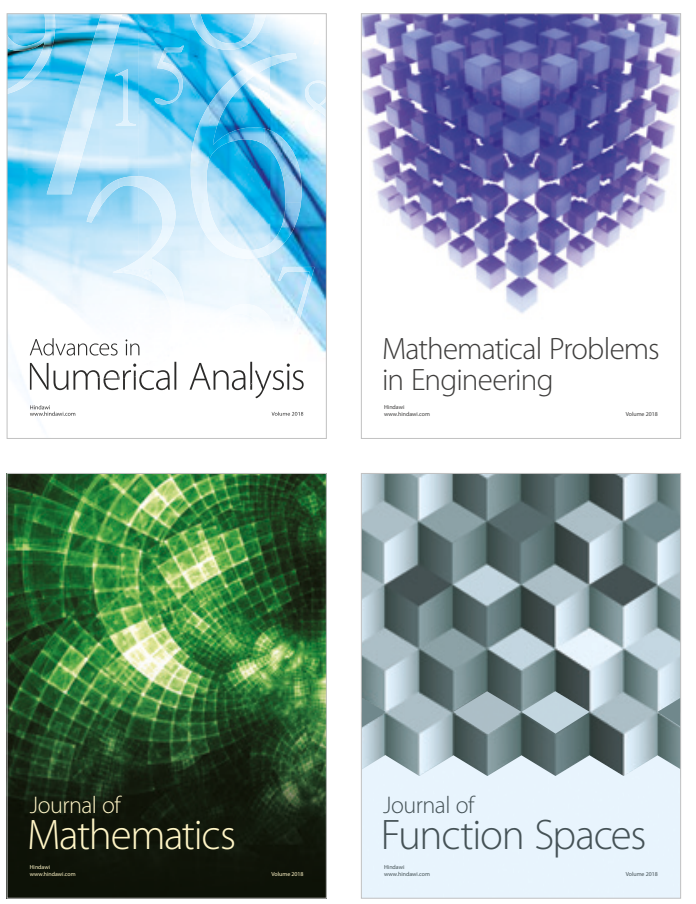

Mathematical Problems in Engineering

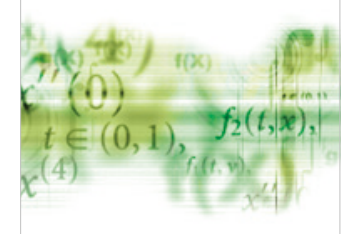

International Journal of

Differential Equations

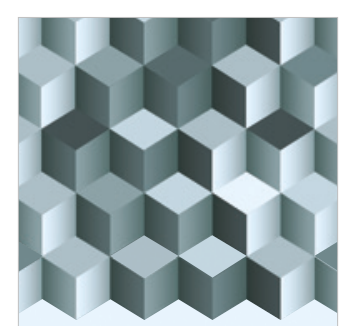

Journal of

Function Spaces

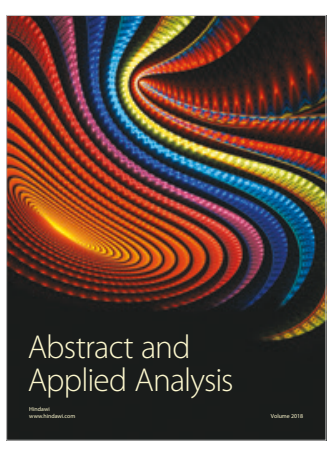

The Scientific

World Journal

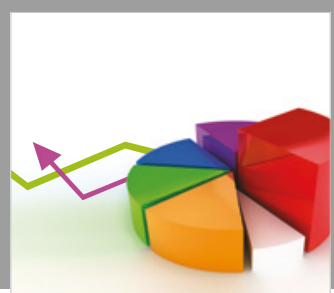

Journal of

Probability and Statistics
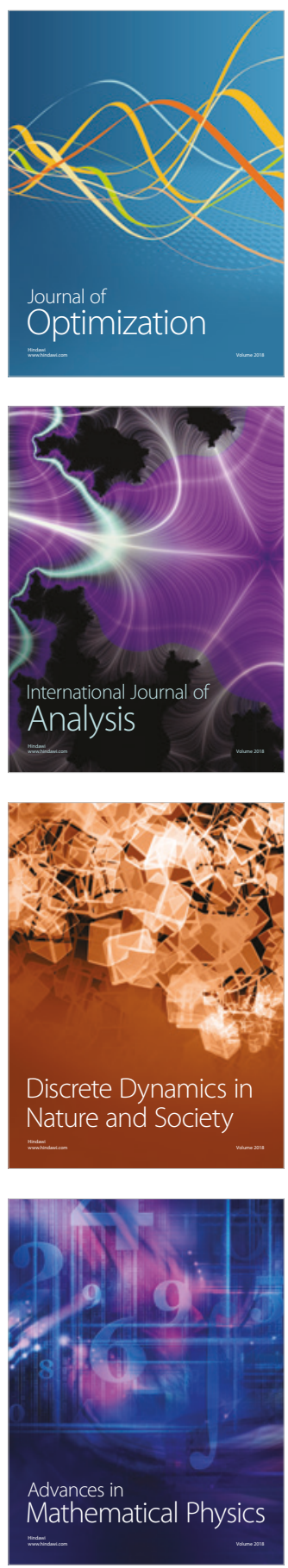